\title{
Democracia, Sociedade Civil Organizada e internet: estratégias de articulação online da Rede Nossa São Paulo
}

\author{
CLAUDIO LUIS DE GAMAREO PENTEADO \\ MARGELO BUREOS PIMENTEL SANTOS" \\ BAFAEL DE PAULA AGUIAR ARAÚJO
}

\section{Resumo}

Com o desenvolvimento das Tecnologias de Informação e Comunicação (TICs) o debate acerca das possibilidades democráticas da internet se intensificou. A arquitetura em rede da internet, somada às ferramentas de interação, tem possibilitado novas formas de organizações sociais e uma criativa agenda de ações políticas, que podem significar um avanço no desenvolvimento dos processos democráticos. Essas tecnologias possibilitam novos mecanismos de comunicação com o Estado e viabilizam novas articulações da sociedade civil. A proposta deste artigo é avaliar a dinâmica da Rede Nossa São Paulo (RNSP), movimento da sociedade civil, formada por cerca de 700 instituições, que atua na região metropolitana de São Paulo, e analisar suas estratégias de articulação através da Web, para a promoção de ações políticas. A avaliação da e-participação na RNSP foi realizada por meio da combinação de três diferentes abordagens: (1) identificação das diferentes formas de e-participação; (2) avaliação das dimensões-chave de e-participação; e (3) classificação da atuação da Rede de acordo com o grau de democracia digital. Os resultados permitem observar que a internet pode auxiliar na promoção de ações democráticas, criando novos mecanismos de atuação da sociedade civil.

Palavras-chave: Internet. Participação política. Sociedade civil. Rede Nossa São Paulo.

\footnotetext{
*Universidade Federal do ABC (Brasil)

** Universidade Federal da Paraíba

${ }^{* * *}$ Pontifícia Universidade Católica de São Paulo (PUC-SP) (Brasil)
} 


\section{Democracy, Civil Society and internet: strategies of online coordination within "Rede Nossa São Paulo"}

\section{Abstract}

The development of Information and Communication Technologies (ICTs) has intensified the debate over the democratic possibilities offered by the Internet. Its network structure, coupled with interaction tools, has enabled new forms of social organizations and a creative agenda for political action, which can mean a step forward in the development of democratic processes. These technologies allow the development of new means of communication between the State and the Civil Society. This paper aims to evaluate the dynamics of Rede Nossa São Paulo (RNSP), a civic movement formed by almost 700 institutions, which operates in the metropolitan area of São Paulo, and to analyze its coordination strategies through the Internet to promote political action. The evaluation of RNSP's e-participation was performed through three approaches: (1) identification of the different forms of e-participation; (2) evaluation of the key dimensions of e-participation; and (3) measuring of RNSP's actions in accordance to the level of digital democracy. The findings allow us to observe that the internet can help in the promotion of democratic actions, creating new ways of political action in Civil Society.

Keywords: Internet. Political participation. Civil society. Rede Nossa São Paulo.

\section{Introdução}

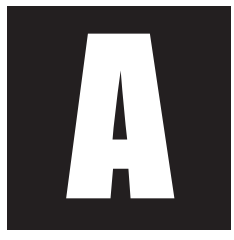

Rede Nossa São Paulo (RNSP) é um movimento da sociedade civil que nasceu dentro de um novo paradigma de organização e funcionamento, a rede. Motivada por valores associados a uma cidadania ativa, a RNSP se autoclassifica como apartidária e inter-religiosa, atuando na mobilização de diferentes segmentos da sociedade, em parceria com instituições públicas e privadas, para construir uma cidade de São Paulo justa e sustentável. 
Esse movimento da sociedade civil opera por meio da formação de uma agenda social construída coletivamente por seus membros e parceiros (organizados em grupos de trabalhos temáticos), articula e promove ações sociais em prol de políticas públicas para a cidade, organiza protestos sociais, desenvolve projetos e programas em articulação com seus membros e parceiros e exerce pressão sobre os representantes políticos.

Dentro da atual configuração social do mundo globalizado, a sociedade civil organizada tende a agir no formato de rede. Assim, articulase com redes de movimentos sociais e atua por meio da formação de parcerias entre as esferas pública, privada e estatal, promovendo uma maior participação dos cidadãos na governança urbana (Scherer-Warren, 2006). O paradigma da rede surge como importante elemento associativo nas relações sociais, econômicas, políticas e tecnológicas do mundo contemporâneo. Sua lógica pode ser utilizada para explicar novas formas de atuação política e social da sociedade civil organizada (Kauchakje et al, 2006; Frey, 2002), que se caracterizam por sua capilaridade, flexibilidade e capacidade para formação de parcerias.

Dentro desse paradigma, a RNSP se apropria do espaço da rede mundial de computadores e seus dispositivos comunicacionais para interagir com os cidadãos, com seus parceiros, com o setor público, e articula suas diferentes ações, programas e projetos. O desenvolvimento das Tecnologias de Informação e Comunicação (TICs) amplia o alcance e a capacidade de mobilização e articulação dos cidadãos, além de possibilitar a maior participação dos atores sociais da sociedade civil. A arquitetura em rede da internet, somada às ferramentas de interatividade e colaboração, tem possibilitado novas formas de organizações sociais e uma criativa agenda de ações políticas que podem significar um avanço no desenvolvimento dos processos democráticos. Essas tecnologias possibilitam novos mecanismos de comunicação com o Estado e viabilizam diferentes articulações da sociedade civil, como é o caso da RNSP. 
Para Castells (1999), as novas tecnologias estão integrando o mundo em redes globais de instrumentalidade, transformando as lógicas de ação social e de operação política e econômica para o formato de rede. A formação das redes de comunicação e informação permite uma maior mobilidade e versatilidade no trânsito da informação. Possibilita, também, compartilhamento e troca de informações entre seus participantes, tornando o processo de comunicação mais fluido e dinâmico, rompendo com o modelo hierárquico tradicional da burocracia empresarial ou estatal. A organização em rede aumenta o poder e a flexibilidade das organizações, que passam a ter maior agilidade e capacidade de produção de informação e conhecimento.

A revolução das TICs tem alterado as relações sociais e produzido novos arranjos políticos da Sociedade em Rede (Castells, 1999). As TICs ganharam uma dimensão central dentro dos processos sociais, atuando como ferramenta e espaço para as práticas políticas contemporâneas, abrindo novas possibilidades para a ampliação de mecanismos de democracia, principalmente dentro de práticas participativas. Dentro desse contexto, este artigo realiza a avaliação de como a RNSP se apropria das ferramentas interativas e colaborativas da internet para incentivar uma maior participação popular em suas ações políticas e promover a participação online (e-participação). O objetivo é verificar em que medida a internet pode ser considerada ou não um facilitador para novas ações democráticas.

$\mathrm{O}$ artigo está estruturado em três partes. Na primeira é discutida a relação entre redes sociais e novas formas de participação cidadã, principalmente por meio da internet; na parte seguinte são destacadas as formas de e-participação em políticas públicas; e na parte final é apresentada uma avaliação da e-participação na RNSP, por meio da combinação de três diferentes abordagens: (1) identificação das diferentes formas de e-participação adotadas nas ações da rede; (2) avaliação das dimensões chave de e-participação; e (3) classificação da atuação da RNSP de acordo com o grau de democracia digital. 


\section{Redes sociais e participação cidadã}

O termo sociedade civil é polêmico dentro das Ciências Sociais. Contudo, para esse estudo, será usada a abordagem de Ilse Scherer-Warren (2006), que utiliza uma noção genérica e contemporânea do conceito que se adéqua ao escopo do artigo:

A sociedade civil, embora configure um campo composto por forças sociais heterogêneas, representando a multiplicidade e diversidade de segmentos sociais que compõem a sociedade, está preferencialmente relacionada à esfera da defesa da cidadania e suas respectivas formas de organização em torno de interesses públicos e valores, incluindo-se o de gratuidade/altruísmo, distinguindo-se assim dos dois primeiros setores acima [Estado e Mercado] que estão orientados, também preferencialmente, pelas racionalidades do poder, da regulação e da economia. É importante enfatizar, portanto, que a sociedade civil nunca será isenta de relações e conflitos de poder, de disputas por hegemonia e de representações sociais e políticas diversificadas e antagônicas (Scherer-Warren, 2006, p. 110).

A partir da definição adotada pela autora, pode-se perceber que a sociedade civil no mundo contemporâneo está associada à defesa da cidadania. No caso brasileiro, para Gohn (2004), a noção de sociedade civil, a partir dos anos 1990, se amplia para ligar-se com sociedade política. Assim, a atuação da sociedade civil passa a estar associada a uma nova organização sociopolítica, pela qual são construídos novos espaços de participação (conselhos, fóruns, etc.) para a atuação de grupos na defesa de seus interesses. A participação cidadã passa a ser desenvolvida através de ações coletivas organizadas e expressas nos espaços públicos pelos diferentes agentes representantes da sociedade civil em suas várias formas de organização e composição.

A partir das variadas formas de articulação da sociedade civil organizada (associativismo local, articulação interorganizacional, mobiliza- 
ções na esfera pública e grupos de apoio financeiro), vai surgir o conceito de rede de movimento social, que pressupõe a identificação de sujeitos coletivos em torno de valores, objetivos ou projetos em comum, os quais definem os atores ou situações sistêmicas antagônicas que devem ser combatidas e transformadas (Scherer-Warren, 2006, p. 113).

Os diferentes atores da sociedade civil organizada (ONGs, movimentos sociais, associações, etc.) cada vez mais se articulam entre si para aumentar sua visibilidade e sua capacidade de atuação e arrecadação; ampliam assim seu poder de influência para produzir conquistas na esfera pública e contribuir para o desenho e a implementação de políticas públicas, configurando uma nova lógica de atuação mais institucionalizada (Gohn, 2010) e organizada em rede (Scherer-Warren, 2006).

A lógica de rede permite às entidades estruturar o não estruturado, preservando a flexibilidade e incentivando a inovação. As redes não são apenas outra forma de estrutura, mas sim uma não estrutura. Sua força está na habilidade de fazer-se e desfazer-se de tempo em tempo. O sistema de rede permite modificações e reconfigurações, de forma a se adaptar às mudanças e alterações constantes da complexidade do mundo atual. Por esse sistema, é possível intervir e modificar as regras sem desmantelar a organização em um processo de deliberação, mantendo a integração da rede e seus componentes (Castells, 1999).

As redes sociais que atuam em contato com a estrutura do Estado emolduram a dinâmica política e influenciam fortemente a formulação e a implementação das políticas públicas (Marques, 2006, p. 15). Segundo Marques (2006), as redes sociais estruturam os campos das relações sociais, criando vínculos entre os indivíduos, entidades e organizações sociais. Considerando a natureza relacional do poder, as relações e posições nas redes formam estruturas que influenciam ou constrangem tomadas de decisão, como também dão acesso diferenciado a recursos e acabam interferindo nos resultados das políticas. 
Em seu estudo sobre redes cívicas e internet, Rousiley Maia (2007, p. 44) avalia como os atores coletivos da sociedade civil se utilizam da internet para alcançar seus propósitos 'potencialmente' democráticos, por meio da disponibilização e da troca de informações, e como meio de coordenar suas ações. Partindo de uma perspectiva habermasiana, a autora identifica diferentes tipos de redes associativas que se apropriam dos recursos da internet para promover efeitos democráticos: interpretação de interesses e construção de identidade coletiva; constituição de esfera pública; ativismo político, embates institucionais e partilha de poder; supervisão e processos de prestação de contas.

Segundo Maia (2007), a internet possibilita a criação de plataformas de diálogos entre os diferentes atores (locais, regionais, nacionais ou transnacionais) ampliando a capacidade de comunicação e atuação, permitindo que muitos indivíduos possam participar das atividades pelo mundo virtual. Os mecanismos comunicacionais da internet criam a oportunidade para que grupos possam se engajar na vida pública, defendam seus interesses, afirmem suas identidades coletivas, participem do debate público, promovam e organizem manifestações (virtuais ou presenciais) e criem mecanismos de controle social (transparência das ações públicas e accountability).

No contexto da Sociedade da Informação, a partir da incorporação das TICs, a dinâmica das redes socais ganha nova configuração, criando ou remodelando as existentes, formando o que Kauchakje et al (2006) e Egler (2010) chamam de redes tecnosociais ou sociotécnicas. Essas representam a incorporação dos instrumentos cooperativos e interativos da internet na articulação e organização das redes sociais.

Os dispositivos da internet criam uma alternativa de redefinição das relações entre Estado e sociedade civil, possibilitando a tessitura de novas relações mediadas pelas redes tecnossociais (Egler, 2010), principalmente na gestão de cidades. As redes tecnossociais podem representar 
uma inovação das relações políticas, que se caracterizam pela estrutura burocrática, centralizada e autoritária, tornando-a mais permeável para a intervenção cidadã, menos rígida, mais descentralizada e democrática.

O modelo de rede tecnossocial oferece formas novas de interação social, cooperação, coordenação e ação política com o potencial de promover uma maior participação cidadã (presencial e virtual) e democratizar a gestão urbana. As redes tecnossociais possibilitam a emergência de um espaço de comunicação virtual de todos para todos, com acesso a um vasto banco de dados que pode orientar a ação dos atores sociais.

As redes tecnossociais, ou sociotécnicas, podem incluir redes sociais, organizações governamentais, empresas privadas e cidadãos comuns, que criam formas de integração da esfera pública com a privada, sustentadas pela infraestrutura comunicacional das TICs, que ampliam a capacidade de participação social, como é o caso da RNSP. Como afirma Egler (2010), a tecnologia permite a ação coletiva e direta de seus membros frente aos problemas sociais da cidade.

Caracterizada por uma arquitetura reticular, líquida e móvel, que se realiza por meio de atos de comunicação, as redes tecnossociais criam condições para que seus membros produzam um sujeito coletivo que atua por ações compartilhadas (Egler, 2010), criando condições para uma maior participação cidadã.

\section{Participação online (e-participação)}

O conceito contemporâneo de sociedade civil tem na participação cidadã seu principal instrumento de ação e na democracia o seu pressuposto básico. A participação cidadã ocorre quando o cidadão toma parte de um processo político, social e cultural por meio de ações coletivas organizadas e expressas em espaços públicos. Tal participação tem várias dimensões, 
dentre as quais se destacam a gestão nos processos de políticas públicas decisórias, o aspecto educativo (pedagógico) e o controle social dos cidadãos sobre as políticas públicas (Gohn, 2010). A participação torna o cidadão mais ativo, fomenta a democracia e permite a formação de um maior engajamento político e a percepção do bem comum (Meijer et al, 2009).

A participação dos cidadãos é considerada um elemento valioso da cidadania democrática, uma vez que pode significar maior eficiência e eficácia para as políticas públicas, principalmente porque os interessados se envolvem na solução dos problemas (Papadopoulos; Warin, 2007). A participação permite ao cidadão dizer diretamente o que deseja; dá voz a indivíduos e minorias geralmente alheias aos processos políticos; encoraja habilidades e virtudes cívicas; estimula a deliberação pública, que pode levar a decisões racionais baseadas na razão pública (bem comum); além disso, aumenta o suporte para os resultados dos processos democráticos (Michels, 2011).

Meijet et al (2009) destacam que a internet oferece novas oportunidades para os cidadãos intervirem na vida política, criando mecanismos para o desenvolvimento de uma participação online, pela qual o uso das ferramentas das TICs possibilita o envolvimento do cidadão na busca de soluções para alguns dos problemas da sociedade. As transformações introduzidas modificam e diversificam as formas de participação civil, criando uma agenda voltada aos estímulos da participação cidadã, e identificam novas possibilidades de intervenção popular na formulação e no processo decisório das políticas públicas (Fung, 2006).

Segundo estudos realizados por Tamborius et al (2007, p. 9), a e-participação, ou participação online, envolve diferente níveis: e-informação (canal de informação para os cidadãos), e-consulta (canal de comunicação online para coletar respostas e alternativas do público), e-envolvimento (que visa assegurar que as preocupações públicas sejam compreendidas e levadas em consideração), e-colaboração (canal interativo entre o cida- 
dão e o governo, pelo qual os primeiros podem participar ativamente do desenvolvimento de alternativas e na identificação de soluções preferidas) e e-empoderamento (que facilita a transferência da influência, controle e formulação de políticas para o público).

Estudando a participação online no processo de políticas públicas, Ann Macintosh (2004) indica que está crescendo o número de exemplos de organizações governamentais que utilizam as TICs para promover o acesso às informações e colher respostas da população sobre as políticas públicas. Para a autora, as TICs possibilitam aos cidadãos participar e influenciar a tomada de decisão, além de permitir o feedback dos mesmos e a transparência das políticas públicas. Macintosh (2004) identifica dez dimensões chave que caracterizam a e-participação:

Quadro 1. Dimensões chave da e-participação

\begin{tabular}{|l|l|}
\hline Dimensão & Descrição \\
\hline 1. Nível de participação & $\begin{array}{l}\text { Qual o nível de participação ou a distância do } \\
\text { engajamento dos cidadãos }\end{array}$ \\
\hline $\begin{array}{l}\text { 2. Estágio de tomada de decisão } \\
\text { (ciclo de políticas públicas) }\end{array}$ & $\begin{array}{l}\text { Qual a etapa do ciclo da política em que ocorre } \\
\text { o engajamento }\end{array}$ \\
\hline 3. Atores & Quais são os atores envolvidos e sua participação \\
\hline 4. Tecnologias utilizadas & $\begin{array}{l}\text { Quais as ferramentas utilizadas para promover o } \\
\text { engajamento }\end{array}$ \\
\hline 5. Regras de engajamento & Quais os procedimentos para a participação \\
\hline 6. Duração e sustentabilidade & Qual o período de tempo que envolve \\
\hline 7. Acessibilidade & Quantos cidadãos participaram e de onde \\
\hline 8. Recursos e promoção & Quanto foi gasto e qual a sua divulgação \\
\hline 9. Avaliação e resultados & Análise dos procedimentos e resultados alcançados \\
\hline 10. Fatores críticos para o sucesso & $\begin{array}{l}\text { Quais os fatores políticos, legais, culturais, } \\
\text { econômicos e tecnológicos que influenciaram }\end{array}$ \\
\hline
\end{tabular}

Fonte: Macintosh (2004, p. 6).

Ao analisar a e-participação, a autora argumenta que as TICs possibilitam maior participação, engajamento e empoderamento da sociedade 
civil no processo de políticas públicas, contribuindo para sua maior efetividade, transparência e democratização. As características interativas e colaborativas dessas tecnologias, conforme apontado acima, possibilitam reformar e democratizar a gestão pública, permitindo uma maior interação entre o Estado e a sociedade civil, mediada pelas estruturas de rede que operam dentro e fora das instituições sociais e políticas.

Gomes (2005) assinala que dentro dos estudos sobre a participação política pela internet existem cinco graus de democracia digital, correspondentes aos modelos de democracia participativa. O primeiro grau está associado à garantia do acesso do cidadão aos serviços públicos através das TICs e na prestação de informações pelos representantes políticos, Estado e partidos políticos. Nesse nível também existem iniciativas voltadas para a agilização da burocracia estatal, melhoria da gestão e diminuição dos custos da administração pública. O nível seguinte é caracterizado pela existência de um Estado que consulta os cidadãos pelos diferentes canais das TICs para averiguar a opinião pública sobre temas da agenda e para a formar a agenda pública. Nesses dois graus iniciais, o autor destaca que o fluxo de comunicação tem como ponto de partida a esfera política institucional, que utiliza as TICs para obter um feedback da esfera civil.

A partir do terceiro grau, o fluxo de informação tem origem em iniciativas da sociedade civil, ou seja, inverte-se a relação da procura, que passa a ser da sociedade. O Estado é caracterizado por um elevado grau de transparência de suas ações, mas as decisões políticas ainda estão sobre sua responsabilidade. O quarto grau da democracia digital corresponde à adoção de mecanismos digitais de deliberação pública, tornando as decisões estatais mais "porosas" à participação popular, indo além da prestação de informações dos graus iniciais. No quinto e último grau, as TICs possibilitam o desenvolvimento de práticas de democracia direta, diluindo a esfera política, que ficaria encarregada da administração pública, 
cabendo à esfera civil a decisão sobre os negócios públicos, formando um Estado governado por plebiscitos.

\section{Rede Nossa São Paulo - participação cidadã online}

A Rede Nossa São Paulo, que atua na zona metropolitana de São Paulo, foi criada originalmente em maio de 2007, com o nome Movimento Nossa São Paulo, alterado para a atual denominação em outubro de 2010. O projeto surgiu a partir da organização da sociedade civil com a intenção de ser um movimento político que procura pautar suas ações a fim de recuperar para a sociedade os valores de desenvolvimento sustentável, da ética e da democracia participativa ${ }^{1}$. A iniciativa procura garantir uma força política para atuar na proposição da agenda de planejamento da cidade, assim como o estabelecimento de metas que são cobradas tanto da Câmara Municipal como também do Poder Executivo. Em sua carta de princípios, a RNSP se apresenta como movimento da sociedade civil, pautado por três pilares democráticos: equidade, participação e transparência.

De acordo com Fiabane (2011), o movimento Rede Nossa São Paulo procura desenvolver suas ações em quatro perspectivas diferentes, a saber: a) programa de indicadores e metas; b) acompanhamento cidadão; c) educação cidadã e; d) mobilização cidadã. Percebe-se, aqui, uma tentativa por parte do movimento de colaborar com a administração da cidade e a governança, estreitando a relação entre poder público e cidadãos em geral. Cabe ressaltar, ainda, que o Programa de Indicadores e Metas se constitui em um banco de dados virtual com os indicadores sociais da prefeitura e subprefeituras, elaborados através de dados oficiais e, pos-

\footnotetext{
${ }^{1}$ Cf. site da RNSP.
} 
teriormente, publicados e disponibilizados, podendo ser acessados via internet por qualquer cidadão.

A RNSP já articulou uma votação pela internet, na qual os cidadãos deveriam priorizar, a partir de uma lista, as suas preferências sobre assuntos relativos à cidade, tais como: educação, saúde, segurança, habitação, lazer, transporte e mobilidade, cultura, meio ambiente, entre outros temas. As preferências da sociedade civil foram elencadas e levadas ao executivo e legislativo como reivindicações que deveriam ser atendidas. Além disso, a RNSP estabelece um plano de metas que deve ser cumprido a cada ano. A Rede conta também com apoio da mídia tradicional, como, por exemplo, o jornal Folha de S. Paulo, que divulga as pesquisas realizadas. Assim, também é possível notar que a RNSP consegue, por vezes, pautar a agenda da mídia tradicional².

A RNSP tem expandido suas ideias e projetos para outros municípios do Brasil, como Suzano, Campinas e a Grande São Paulo. Por exemplo, o Fórum de Cidades Sustentáveis, organizado pela RNSP, serviu de modelo para ação semelhante em outras cidades, como o Rio de Janeiro. A iniciativa reverbera um novo modelo de deliberação política via internet, capaz de articular a sociedade civil e exercer pressão no Estado.

\subsection{Avaliação da e-participação na Rede Nossa São Paulo}

Para realizar a avaliação da e-participação na RNSP, foi utilizada a combinação de três diferentes abordagens: (1) identificação das diferentes formas de e-participação adotada nas ações da rede; (2) avaliação

\footnotetext{
${ }^{2}$ Por exemplo, no dia 5 de fevereiro, a FSP publicou reportagem sobre a desigualdade paulistana com base em pesquisa feita pela RNSP. Além disso, uma semana antes, havia publicado artigo de Oded Grajew sobre a mesma temática. Disponível em: $<\underline{\text { http://www1.folha.uol. }}$ com.br/fsp/cotidiano/24153-estudo-escancara-desigualdade-paulistana.shtml > . Acesso em: 05 fev. 2012. e <http://www1.folha.uol.com.br/fsp/opiniao/22778-cidade-desigual.shtml >. Acesso em: 29 fev. 2012.
} 
das dimensões chave de e-participação; e (3) classificação da atuação da RNSP de acordo com o grau de democracia digital.

A identificação das formas de e-participação seguiu as categorias sugeridas por Tamborius et al. (2007), incorporando a e-mobilização, uma vez que as classificações sugeridas pelos autores estavam relacionadas às experiências desenvolvidas por parte da administração pública. Como a RNSP é uma iniciativa da sociedade civil, existem ações voltadas para a mobilização popular que usam os canais de comunicação da internet (portais, blogs, redes sociais, etc.) para divulgar, articular e organizar manifestações.

Para a avaliação das dimensões chave de e-participação foram utilizadas as categorias listadas anteriormente, desenvolvidas por Macintosh (2004).

Por fim, a atuação da RNSP foi classificada de acordo com o seu grau de democracia digital, a partir dos cinco níveis explicitados por Gomes (2005). A combinação desses três procedimentos possibilitou uma avaliação geral de como a RNSP está se apropriando do espaço de comunicação e das ferramentas interativas da internet para promover uma maior participação cidadã e aumentar a eficiência de suas ações.

4.1.1 Identificação das diferentes formas de e-participação adotadas nas ações da RNSP:

1. Campanha você no Parlamento:

a) Descrição da ação: projeto em parceria com a Câmara Municipal de São Paulo que, por meio de um questionário (impresso e online), buscou identificar as prioridades da população paulistana em diversas áreas (saúde, educação, etc.) para pautar a atuação dos vereadores. O questionário foi desenvolvido por uma comissão técnica formada por representantes da RNSP, Câmara, USP, FGV, Escola de Governo e Ibope, com base nos IRBEM (Indicadores de Referência de Bem-Estar do Município), e elaborado pela RNSP e pelo Ibope. A consulta pública foi realizada 
no período de 15 de junho a 30 de setembro de 2011. A ideia é que os resultados orientem a formulação de políticas públicas, projetos de lei e a fiscalização do Executivo, de forma que os gestores públicos atuem de acordo com as necessidades apontadas pela população. A ação foi divulgada em diversas mídias: Folha de S. Paulo, Revista Época, Metro News, Jornal da Gazeta, etc.

b) Uso da internet: e-informação; e-mobilização; e-consulta; e-envolvimento. Por meio das informações disponíveis no portal da rede, o cidadão poderia orientar e qualificar sua participação. A internet também foi utilizada como um meio de divulgação, inclusive com orientações para esse fim, sendo que os cidadãos poderiam inserir o banner da campanha em seus sites e portais, imprimir e distribuir o cartaz, promover nas redes sociais e divulgar o link em seus e-mails. O meio digital também foi empregado para o preenchimento do questionário com as opiniões da população, facilitando a participação do cidadão.

2. IRBEM (Indicadores de Referência de Bem-Estar do Município):

a) Descrição: essa ação da Rede teve início em junho de 2009 com a realização de uma consulta pública que forneceu subsídios para a realização da pesquisa Ibope, em janeiro de 2010, sobre a satisfação da população em relação aos itens mais citados nas consultas, permitindo a criação de indicadores. O objetivo dessa ação era orientar ações governamentais e da sociedade civil na promoção do bem estar das pessoas. A pesquisa também abordou o índice de confiança da população nas instituições, a satisfação com os serviços públicos e a administração municipal e a percepção sobre a segurança na cidade. O IRBEM já está na sua terceira edição (2010, 2011 e 2012).

b) Uso da internet: e-informação; e-mobilização; e-envolvimento; e-consulta. Por meio do portal da RNSP, os cidadãos podem acessar os resultados das pesquisas e os índices, disponíveis no Observatório Cida- 
dão. A mobilização online foi realizada através de incentivos para a participação na consulta com notícias no portal. A consulta pública, além da versão impressa, também foi realizada no formato online.

3. Indicadores:

a) Descrição: na seção Observatório Cidadão, a Rede disponibiliza, além do IRBEM, outros indicadores sociais, ambientais, econômicos, políticos e culturais da cidade de São Paulo e de cada uma de suas subprefeituras.

b) Uso da internet: e-informação; e-envolvimento. Além de disponibilizar os indicadores para consulta e localizar no mapa (dentro do Observatório Cidadão), os usuários também podem fazer download dos indicadores de 2008 e 2009.

4. Programa Cidades Sustentáveis:

a) Descrição: a RNSP integra um programa chamado Rede Latinoamericana por Cidades Justas, Democráticas e Sustentáveis, formado por diversas cidades que buscam a execução de boas práticas cidadãs. Durante as eleições, a Rede apresenta aos candidatos uma agenda de sustentabilidade urbana como referência para a gestão pública, pressionando os políticos a assumirem compromisso com o programa e fazendo campanha para que os eleitores valorizem os candidatos comprometidos com as metas.

b) Uso da internet: e-informação; e-mobilização; e-envolvimento; e-colaboração. Esse programa da RNSP apresenta diversas ferramentas que se apropriam da Web. Na parte de informações online, além do portal Programa Cidades Sustentáveis, a RNSP também divulga suas ações dentro de outras mídias sociais, como Facebook, Twitter, Canal de Vídeos no Youtube e Google+. Dentro desses espaços os usuários também podem ter acesso à agenda e às ações do programa. Na parte de e-mobilização, o programa utiliza seus diferentes canais na internet em campanhas para que os candidatos adotem a plataforma e sigam o programa, podendo aderir à carta de compromisso. 
Também há campanhas para que os cidadãos votem nos candidatos comprometidos com o Programa Cidades Sustentáveis. Como mecanismos participativos por parte da Sociedade Civil, há o banco de boas práticas (nesse local, os cidadãos podem apresentar propostas, aprimorar as existentes e dar indicações para a biblioteca virtual) além da possibilidade de propor parcerias para articular e mobilizar grupos a fim de discutir sustentabilidade nos municípios, estabelecer um canal de diálogo com o poder público local e utilizar as ferramentas do Programa Cidades Sustentáveis, disponíveis online. Também é possível a proposição de políticas públicas a partir de diagnósticos, e compartilhar e divulgar ações desenvolvidas pela Rede ou outras redes das quais o cidadão participe.

5. Fórum Empresarial de apoio à cidade de São Paulo:

a) Descrição: ação em parceria com o Instituto Ethos que tem a finalidade de sensibilizar, mobilizar e assessorar as empresas para que atuem incentivando o desenvolvimento justo e sustentável de São Paulo, por meio de parcerias com outras empresas, organizações sociais, instituições de ensino e pesquisa e o poder público.

b) Uso da internet: e-informação; e-envolvimento; e-colaboração. O Fórum disponibiliza um site com informações sobre as práticas adotadas com notícias, fotos, vídeos e publicações. O portal também oferece para seus usuários a ferramenta Mapa de Práticas, que possibilita cadastro e pesquisa de projetos na cidade de São Paulo. Outro recurso existente é a Cartografia do Investimento Social por meio de georreferenciamento, que permite às empresas interessadas identificar áreas potenciais para investimentos sociais.

6. Formação de lideranças:

a) Descrição: atividade desenvolvida em 2010 que teve como objetivo a formação de lideranças políticas comunitárias, por meio de diversos encontros regionais. A formação é realizada por membros da Rede em 
conjunto com movimentos sociais (Fórum em Defesa da Vida, Movimento Nossa Zona Leste, além de lideranças comunitárias, como Padre Jaime, Padre Tição, entre outros) nas 31 subprefeituras, que têm como um eixo central a participação popular na elaboração de políticas públicas, e a intervenção da população no planejamento da cidade.

b) Uso da internet: e-mobilização; e-envolvimento. Nessa ação, o uso das ferramentas da Web é restrito para a divulgação das reuniões e para os interessados entrarem em contato via e-mail.

7. Debates sobre mobilidade e transporte:

a) Descrição: parceria com a Câmara Municipal de São Paulo, realizada entre maio e novembro de 2010, que promoveu uma série de seminários intitulada "Mobilidade e Transporte Sustentáveis". Esse evento construiu uma agenda de propostas sobre o tema com participação da sociedade civil e poder público.

b) Uso da internet: e-informação. Nesse caso, também houve pouco uso da Web. Contudo, está disponível para download uma versão resumida e completa do plano, e as suas principais diretrizes estão disponíveis para leitura na seção.

8. Dia Mundial sem carro:

a) Descrição: evento que ocorre junto com a Semana de Mobilidade, visando estimular a construção de uma agenda de mobilidade urbana e interferência em políticas públicas, com início em 2007. A intenção é estimular as pessoas a utilizarem formas alternativas de transporte.

b) Uso da internet: e-informação; e-mobilização; e-envolvimento. Por meio do site e de um blog, os usuários podem tomar conhecimento das ações e da pesquisa da RNSP com o Ibope sobre o Dia Mundial sem Carro. A Web é utilizada para a mobilização da população e adesão de empresas. A campanha também está nas redes sociais ligadas à RNSP. Os usuários podem baixar no blog o "kit de mobilização". 
9. Campanha pela redução da taxa de enxofre no diesel vendido no País:

a) Descrição: a RNSP participa do movimento que defende a limitação do teor de enxofre no óleo diesel, atendendo à resolução do CONAMA. Com essa ação, a Rede visa cobrar a adoção de políticas para a melhoria das condições do ar.

b) Uso da internet: e-informação; e-mobilização. A RNSP disponibiliza em seu portal uma série de informações sobre o tema, apresentando estudos e dados sobre os riscos da queima do enxofre para a saúde. No portal, existem diversos mecanismos de mobilização e adesão à campanha.

10. Programa de Metas - emenda à Lei Orgânica do Município

a) Descrição: como resultado da ação da RNSP, foi criada uma emenda à Lei Orgânica do Município, em fevereiro de 2008, que obriga os prefeitos a apresentarem um programa de governo semestral, com metas e prestação de contas. O objetivo é firmar um compromisso do prefeito com seu programa de governo.

b) Uso da internet: e-informação; e-empoderamento. Nesse caso, existe a criação de instrumentos de prestação de contas online, com um termômetro das ações realizadas de acordo com as metas. Os cidadãos também podem acompanhar mais informações sobre as metas do prefeito no site Agenda 2012, com informações e relatórios gerenciados pela própria prefeitura.

\section{Nossa São Paulo na Câmara}

a) Descrição: esta ação publica na página principal as notícias relevantes sobre o funcionamento da Câmara e as leis aprovadas, com intenção de auxiliar o acompanhamento e a divulgação dos trabalhos dos vereadores. Também leva a links da própria Câmara Municipal de São Paulo e dispõe aos cidadãos três formas de interação com o Legislativo municipal, a saber: a) falar com os vereadores da Câmara Municipal; b) agenda de eventos da Câmara Municipal; e c) audiências públicas da 
Câmara Municipal. Todas essas ações levam ao portal da Câmara Municipal. A primeira leva às páginas internas de cada vereador com uma pequena biografia, projetos apresentados, formas de contato e mandato participativo (pelo qual o cidadão se inscreve para receber informações dos mandatos de vereadores). A segunda mostra a agenda de eventos da Câmara e a terceira publica as convocatórias de audiência pública com datas, horários e locais onde ocorrem.

c) Uso da internet: e-participação, e-consulta, e-envolvimento; eempoderamento. O papel da RNSP é colocar os cidadãos em contato direto com as atividades da Câmara e, mais especificamente, com os vereadores. Dessa maneira, fomenta a participação cidadã com informações básicas da Câmara e disponibiliza informações para maior envolvimento e participação cidadã no município de São Paulo.

12. Orçamento per capita e indicadores socioeconômicos por subprefeituras

a) Descrição: a intenção é divulgar o orçamento do município no ano de 2007, com base em pesquisas elaboradas pelo Grupo de Trabalho da Rede Nossa São Paulo. Os dados são calculados tendo por base as informações das 31 subprefeituras da cidade. De acordo com o portal, a ideia é colaborar no processo de acompanhamento dos gastos públicos como forma de combate à corrupção. Não há disponibilização do mesmo estudo referente aos anos subsequentes.

b) Uso da internet: e-consulta; e-empoderamento. Com o intuito de auxiliar em mecanismos de accountability, a RNSP elaborou um documento em formato PDF para ser disponibilizado para a população, com os dados referentes ao ano de 2007.

13. Pesquisa Ibope

a) Descrição: um dos grandes parceiros da RNSP, o Ibope auxiliou no desenvolvimento de diversas pesquisas de indicadores (sobretudo no 
IRBEM), que ajudam a compreender as diferenças entre os diversos territórios e subprefeituras da cidade. Também realiza pesquisas mais pontuais como as publicadas por ocasião do Dia Mundial sem Carro.

b) Uso da internet: e-consulta. A ferramenta com as pesquisas fica à disposição dos interessados no portal.

14. Rede social brasileira por cidades justas e sustentáveis

a) Descrição: esta ação foi lançada em 2008, em Belo Horizonte, composta por organizações apartidárias e inter-religiosas, com intuito de trocar e fomentar as experiências locais. A ideia é comprometer eticamente a sociedade civil e os governos com o futuro das sociedades. Também guarda relação com o Programa Cidades Sustentáveis (já descrito). Além de contar com uma articulação de cidades brasileiras, também conta com diálogos com várias outras cidades que já aderiram à Rede.

b) Uso da internet: e-consulta; e-empoderamento. Além das informações básicas sobre a Rede, também há um programa de metas a serem seguidas pelos prefeitos. Em São Paulo, a RNSP conseguiu que o prefeito assumisse o compromisso com o plano de metas estabelecido. No portal, ficavam disponibilizadas quais as metas cumpridas e a porcentagem dessas em relação ao total assumido. Algumas cidades, inclusive, aprovaram, em seus respectivos Legislativos, leis que incorporam o programa de metas, como fez a própria cidade de São Paulo.

15. 1ํo Fórum Nossa São Paulo

a) Descrição: o evento foi realizado em 2008 com a intenção de formular propostas para os desafios administrativos da metrópole. Foram realizados diversos encontros e parcerias com outras organizações para acolher o maior número possível de propostas. Cerca de 1500 propostas foram elaboradas e entregues aos candidatos a prefeito naquelas eleições, com a expectativa de que fossem incorporadas em suas respectivas campanhas eleitorais. 
b) Uso da internet: e-participação; e-envolvimento; e-empoderamento; e-colaboração. Com encontros presenciais, a RNSP ouviu diversos atores da sociedade civil, perguntando como os mesmos poderiam propor ideias a serem incorporadas pelos gestores públicos na administração da cidade.

16. Eleição 2008

a) Descrição: série de encontros, realizados às vésperas das eleições, com candidatos à Prefeitura Municipal e à Câmara Municipal. Nesses encontros, os candidatos ficavam a par das propostas elaboradas pelos integrantes do 10 Fórum Nossa São Paulo, o que demonstra a atuação da Rede. Também contou com apoio das organizações Voto Consciente e SESC Consolação.

b) Uso da internet: e-consulta. Como os encontros eram presenciais, a internet foi utilizada como plataforma de consulta e divulgação.

17. Conexões Sustentáveis: São Paulo-Amazônia

a) Descrição: a partir de um seminário organizado em outubro de 2008, esta proposta surge com a intenção de mobilizar as cadeias produtivas de madeira, pecuária e soja para a preservação da Amazônia e povos indígenas. Foram produzidos documentos contra o trabalho escravo e que zelam pela certificação dos produtos. A ideia é ampliar a conscientização, através de campanhas, de consumidores e também de produtores. Os termos de compromissos dos signatários são acompanhados por um comitê interno. Os candidatos à Prefeitura em 2008 também foram signatários desse documento, que conta com apoio de diversas associações da sociedade civil e empresarial.

b) Uso da internet: e-participação; e-consulta; e-empoderamento. Ficaram disponibilizadas na internet as ações derivadas desse projeto e seus canais de participação. Os cidadãos podiam consultar as entidades participantes, e também a "lista suja" de quem produz com trabalho escravo ou sem respeito ao meio ambiente. 


\subsubsection{Avaliação das dimensões-chave de e-participação}

\section{Os resultados da avaliação das dimensões-chave estão expostas abaixo:}

Quadro 2. Dimensões chave da RNSP.

\begin{tabular}{|c|c|}
\hline Dimensão & Rede Nossa São Paulo \\
\hline $\begin{array}{l}\text { 1. Nível de } \\
\text { participação }\end{array}$ & $\begin{array}{l}\text { A participação pode ocorrer via instituições da sociedade civil que } \\
\text { apoiam o movimento. Demais usuários podem participar de enquetes e } \\
\text { obter informações (muito variadas) sobre os assuntos, projetos e acom- } \\
\text { panhamentos realizados pela RNSP. }\end{array}$ \\
\hline $\begin{array}{l}\text { 2. Estágio na toma- } \\
\text { da de decisão (ciclo } \\
\text { de políticas } \\
\text { públicas) }\end{array}$ & $\begin{array}{l}\text { Influência sobre a agenda midiática e parlamentar da cidade de São } \\
\text { Paulo. Apresentação de informações das pesquisas realizadas, transpa- } \\
\text { rência governamental e formulação de encontros e simpósios para dis- } \\
\text { cussões e deliberações políticas. }\end{array}$ \\
\hline 3. Atores & $\begin{array}{l}\text { a) Instituição: cerca de } 700 \text { instituições participantes da RNSP. } \\
\text { b) Cidadãos: usuários que acessam o portal para obter informações e } \\
\text { participar de enquetes. }\end{array}$ \\
\hline $\begin{array}{l}\text { 4. Tecnologias } \\
\text { utilizadas }\end{array}$ & $\begin{array}{l}\text { Ferramentas digitais utilizadas para consulta pública: } \\
\text { a) Portal de acesso com fórum de debate, informações sobre projetos, } \\
\text { mecanismos de accountability, sistematização de dados públicos, notí- } \\
\text { cias, contato com vereadores e criação de indicadores. } \\
\text { b) Serviço de telefonia: há um número de telefone e o endereço do } \\
\text { escritório, mas as ações são articuladas através da internet. }\end{array}$ \\
\hline $\begin{array}{l}\text { 5. Regras de } \\
\text { engajamento }\end{array}$ & $\begin{array}{l}\text { As instituições parceiras devem se associar à RNSP. Cidadãos podem } \\
\text { solicitar o envio de newsletter após cadastramento. }\end{array}$ \\
\hline $\begin{array}{l}\text { 6. Duração e } \\
\text { sustentabilidade }\end{array}$ & $\begin{array}{l}\text { As informações são constantemente publicadas e ficam disponíveis con- } \\
\text { forme a duração dos programas. As enquetes de participação popular } \\
\text { têm periodicidade previamente marcada. }\end{array}$ \\
\hline 7. Acessibilidade & $\begin{array}{l}\text { Site de simples navegação. As informações estão disponibilizadas na } \\
\text { própria página principal. Há links para outras iniciativas da sociedade } \\
\text { civil organizada, além de banners com projetos realizados e por realizar. }\end{array}$ \\
\hline $\begin{array}{l}\text { 8. Recursos e } \\
\text { promoção }\end{array}$ & $\begin{array}{l}\text { Divulgação em outras mídias, como jornal, rádio e envio de newslet- } \\
\text { ter para pessoas cadastradas. Divulgação de alguns estudos na mídia } \\
\text { tradicional. }\end{array}$ \\
\hline $\begin{array}{l}\text { 9. Avaliação e } \\
\text { resultados }\end{array}$ & $\begin{array}{l}\text { Os resultados de enquetes e participação popular são tabulados e dis- } \\
\text { ponibilizados em documentos para consulta no site. Também são le- } \\
\text { vados para outros espaços de discussão política, como a Câmara dos } \\
\text { Vereadores }\end{array}$ \\
\hline
\end{tabular}

continua... 
continuação

\begin{tabular}{|l|l|}
\hline Dimensão & Rede Nossa São Paulo \\
\hline $\begin{array}{l}\text { 10. Fatores críticos } \\
\text { para o sucesso }\end{array}$ & $\begin{array}{l}\text { Repercussão na mídia tradicional ajuda na divulgação de estudos e } \\
\text { propostas desenvolvidos pela Rede Nossa São Paulo. Apoio de diversas } \\
\text { instituições (com diferentes ideologias), como associações empresariais, } \\
\text { religiosas, educacionais, ONGs, entre outras entidades. }\end{array}$ \\
\hline
\end{tabular}

Fonte: elaboração dos autores.

Os dados expostos acima ilustram que a e-participação na RNSP pode ocorrer dentro de um amplo leque de possibilidades. A Rede se caracteriza por associar os mecanismos de atuação tradicionais dos movimentos sociais com as ferramentas de interação e colaboração da internet.

\subsubsection{Classificação da atuação da RNSP de acordo com o grau de democracia digital}

É possível identificar o grau 3 (três) de democracia digital, a partir da escala citada por Gomes (2005), para os mecanismos estabelecidos pela RNSP, pelo fato de a iniciativa partir da sociedade civil e por suas ações possibilitarem uma maior transparência do Estado. Não se trata ainda de um modelo capaz de viabilizar decisões e participação direta por parte da população com ações plebiscitárias, pois as decisões ainda ficam a cargo do governo. Há limitações na ação da RNSP no Estado, no entanto, ela é capaz de influenciar a agenda, a implementação e a avaliação de políticas públicas.

\section{Considerações finais}

Manuel Castells, em Redes de indignação e esperança (2013), chama atenção para as relações de poder constitutivas da sociedade. Segundo o autor,

As relações de poder estão embutidas nas instituições da sociedade, particularmente nas do Estado. Entretanto, uma vez que as sociedades são contraditórias e conflitivas, onde 
há poder há também contrapoder - que considero a capacidade de os atores sociais desafiarem o poder embutido nas instituições da sociedade com o objetivo de reivindicar a representação de seus próprios valores e interesses. (Castells, 2013, p. 14).

O mundo contemporâneo tem passado por mudanças importantes. Castells avalia a forma como os homens constituem significações a partir da interação em rede e, nesse processo, são capazes de construir teias de poderes e contrapoderes. Para o autor, nos últimos anos, precisamente desde 2010, as relações de poder têm sido alteradas pelo ambiente da comunicação, esse espaço de trocas de significados e de constituição de poderes. Segundo Castells, a mudança fundamental foi a emergência do que chamou de autocomunicação - o uso da internet e das redes sem fio como plataformas da comunicação digital (Castells, 2013, p. 15). A possibilidade de uma comunicação autônoma e horizontal, que dificilmente é controlada por governos e empresas, representa uma nova dinâmica na relação entre governantes e governados e implica uma nova realidade para o exercício de pressão por parte da sociedade civil.

Em nossa sociedade, que conceptualizei como uma sociedade em rede, o poder é multidimensional e se organiza em torno de redes programadas em cada domínio da atividade humana, de acordo com os interesses e valores de atores habilitados. As redes de poder o exercem sobretudo influenciando a mente humana (mas não apenas) mediante as redes multimídia de comunicação de massa. Assim, as redes de comunicação são fontes decisivas de construção do poder (Castells, 2013, p. 16).

Este artigo toma a RNSP com o intuito de dar materialidade a esse contexto de formação de um contrapoder capaz de exercer pressão sobre o Estado e influenciar o ciclo de desenvolvimento de políticas. Trata-se de uma organização que se apropria da organização em rede e do contexto de au- 
tocomunicação descrito por Castells, mas mantém estratégias inspiradas em modelos antigos. Esse hibridismo assegura uma maior efetividade de atuação da Rede no contexto de transição da cena política dos últimos anos.

A RNSP congrega uma quantidade grande de instituições e de personalidades, que emprestam a ela um poder simbólico significativo. Mesmo funcionando no modelo de rede, esses atores assumem um papel de destaque e acabam por centralizar as ações, dando a elas maior visibilidade.

Por não estar somente associada a entidades e organizações ligadas a uma "esquerda", a RNSP apresenta uma estrutura altamente heterogênea, permitindo que diferentes interesses possam convergir para ações efetivas, como mostram as ações já realizadas e as que estão em andamento. O modelo de rede também possibilita a articulação com outras redes sociais, ampliando suas conexões e seu espectro de atuação.

O espaço da internet é um importante meio para a divulgação de suas ações e resultados alcançados. As ferramentas de comunicação ampliam a possibilidade de participação cidadã, criando condições para uma atuação mais efetiva dos membros e da população em geral.

Os dados coletados indicam que o principal uso da internet é voltado para a divulgação de informação (e-informação). Apesar de ser uma forma limitada de participação online, dadas as possibilidades que as TICs criam, a divulgação das informações via internet é muito importante nesse caso, pois permite uma qualificação do cidadão, informando sobre serviços públicos e indicadores, além de possibilitar transparência para as ações do poder público, como é o caso da Agenda 2012. A e-informação disponibilizada nos fóruns digitais associados à Rede (Portal da RNSP, Observatório Cidadão e outros) cria condições para uma participação do cidadão no debate público (fóruns, conselhos, conferências, etc.) e em iniciativas participativas (consultas, abaixo-assinados, petições, etc.), como também fomenta uma cultura cívica mais participativa. 
Percebe-se uma tendência de maior uso da internet nas novas ações promovidas pela Rede, que estão utilizando mais as ferramentas de participação online, como foi o caso da campanha "Você no Parlamento", pela qual o cidadão teve um papel central ao indicar suas prioridades, encaminhadas à Câmara Municipal de São Paulo. As redes sociais estão se tornando um espaço importante de articulação, mobilização e divulgação das ações. Nota-se a escassez de fóruns virtuais de debate, contudo a RNSP realiza diversos encontros (fóruns, debates, etc.) presenciais entre seus membros, abertos para a participação da população.

Utilizando as formas de interação entre as organizações cívicas estabelecidas através da internet, propostas por Maia (2007), pode-se considerar que (a) em relação à interpretação de interesses e à construção de identidade coletiva, a RNSP consegue agregar e direcionar os diferentes interesses e identidades na direção de valores associados a uma concepção de "cidade justa e sustentável"; (b) na constituição de esfera pública, sua atuação online é limitada, mas presencialmente é realizada, ainda que com pouca participação do cidadão comum; (c) no ativismo político e embates institucionais, a RNSP tem uma efetiva participação online na divulgação, articulação e mobilização de suas ações; e (d) na supervisão de processos de prestação de contas, a Rede se destaca por apresentar diversas ferramentas online, como a Agenda 2012, o IRBEM, Mapas e outros dispositivos.

Por fim, avaliando a RNSP e suas estratégias, é possível considerar que a internet é um facilitador de novas ações democráticas, pois cria mecanismos que possibilitam a e-participação, como apresentado ao longo do texto. Entretanto, ainda é possível avançar em novas experiências e ampliar os mecanismos de participação de forma a integrar mais o cidadão ao debate político e fomentar uma cultura cívica ainda mais participativa. 
Claudio Luis de Camargo Penteado - Doutor em Ciências Sociais pela Pontifícia Universidade Católica de São Paulo. Professor nos Programas de Pós-Graduação em Ciências Humanas e Sociais e Energia da Universidade Federal do ABC (Brasil). $\gg$ claudio.penteado@ufabc.edu.br

Marcelo Burgos Pimentel Santos - Doutor em Ciências Sociais pela Pontifícia Universidade Católica de São Paulo. Professor de Sociologia e Ciência Política no Departamento de Ciências Sociais da Universidade Federal da Paraíba.

$\gg$ marceloburgos@uol.com.br

Rafael de Paula Aguiar Araújo - Doutor em Ciências Sociais pela Pontifícia Universidade Católica de São Paulo. Professor do Departamento de Política da PUCSP e editor da Revista Aurora (Brasil). $\$ rafa77@uol.com.br

\section{Referências}

1. ARAUJO, R., PENTEADO, C. e SANTOS, M. Sociedade Civil Organizada e Novas Tecnologias de Comunicação e Informação: ação cidadã e implementação de políticas públicas na cidade de São Paulo. $3^{\circ}$ Encontro anual da ANPOCS, 2012. Caxambu. Disponível em: <http://www.anpocs.org/portal/arquivos/35_Encontro/ GTs/GT01/ ARAUJO_BURGOS_PENTEADO.pdf>. Acesso em: 18 mar. 2013.

2. ARAUJO, R., PENTEADO, C. e SANTOS. Internet e políticas públicas: web 2.0 como estratégia de debate e divulgação. 34 ${ }^{\circ}$ Encontro anual da ANPOCS, 2010. Caxambu. Disponível em: <http://www.anpocs.org.br/portal/seminarios_tematicos/ST02/PAraujo.pdf>.Acesso em: 18 mar. 2013.

3. CASTELLS, M. Sociedade em Rede. Vol. I. São Paulo: Paz e Terra, 1999.

4. CASTELLS, M. Redes de indignação e esperança: movimentos sociais na era da internet. Rio de Janeiro: Zahar, 2013.

5. EGLER, T. T. C. Redes tecnossociais e democratização das políticas públicas. Sociologias, Porto Alegre, v. 12, n. 23, p. 208-236, 2010.

6. FIABANE, D. Controle Social: um novo frame nos movimentos sociais. 2011. 180 f. Dissertação (Mestrado em Administração Pública) - Escola de Administração de Empresas de São Paulo, Fundação Getúlio Vargas, São Paulo, 2011.

7. FREY, K. Governança eletrônica. Experiências. de cidades européias e algumas lições para países em desenvolvimento. In: EISENBERG, J.; CEPIK, M. (Orgs.). Internet e política: teoria e prática da democracia eletrônica. Belo Horizonte: UFMG, 2002. 
8. FUNG, A. Empowered Participation: Reinventing Urban Democracy. Princeton: Princeton University Press, 2006.

9. GOMES, W. A democracia digital e o problema da participação civil na decisão política. Revista Fronteiras, São Leopoldo, v. 7, n. 3, p. 214-222, set./dez. 2005.

10. GOHN, M. G. Ações coletivas civis na atualidade: dos programas de responsabilidade/ compromisso social às redes de movimentos sociais. Ciências Sociais Unisinos, São Leopoldo, v. 46, n. 1, p. 10-17, jan./abr. 2010.

11. GOHN, M. G. Empoderamento e participação da comunidade em políticas sociais. Saúde e Sociedade, São Paulo, v. 13, n.2, p. 20-31, mai./ago. 2004.

12. KAUCHAKJE, S. et al. Redes socio-técnicas y participación ciudadana: propuestas conceptuales y analíticas para el uso de las TICs. Redes: revista hispana para el análisis de redes socials, Barcelona, v. 11, n. 3, dic. 2006.

13. MACINTOSH, A. Characterizing e-participation in policy-making. Proceedings of the 37th Annual Hawaii International Conference on System Sciences, Hawaii. Computer Society Press, 2004. Disponível em: < http://unpan1.un.org/ intradoc/groups/public/documents/un-dpadm/unpan038449.pdf $>$. Acesso em: 16 mar. 2014.

14. MAIA, R. C. M. Redes cívicas e internet: efeitos democráticos do associativismo. Logos 27: mídia e democracia, Rio de Janeiro, ano 14, n. 27, p. 43-62, $2^{\circ}$ semestre, 2007.

15. MARGetTS, H. (2009), The internet and Public Policy. Policy and internet, Oxford, v.1, n.1, p. 1-21, Dec. 2009.

16. MARQUES, E. C. Redes sociais e poder no Estado brasileiro: aprendizados a partir das políticas urbanas. Revista Brasileira de Ciências Sociais, São Paulo, v. 21, n. 60, p. 15-41, 2006.

17. MEIJER, A., BURGER, N.; EBBERS, W. Citizens4Citizens: Mapping participatory practices on the internet. Electronic Journal of e-Government, Reading, v.7, n.1, p. 99-112, 2009.

18. MICHELS, A. Innovations in democratic governance: how does citizen participation contribute to a better democracy? International Review of Administrative Sciences, UK, v. 77, n. 2, p. 275-293, 2011.

19. MIGUEL, L. F. Representação política em 3-D: elementos para uma teoria ampliada da representação política. Revista Brasileira de Ciências Sociais, São Paulo, v. 18, n.51, p. 123-140, fev. 2003.

20. PAPADOPOULOS, Y.; WARIN, P. Are innovative, participatory and deliberative procedures in policy making effective and democratic? European Journal of Political Research, v. 46, n. 4, p. 445-472, 2007. 
21. SAMPAIO, R. C. Participação política e os potenciais democráticos da internet. Debates, Porto Alegre, v.4, n.1, p. 29-53, jan./jun. 2010.

22. SCHERER-WARREN, Ilse. Das mobilizações às redes de movimentos sociais. Sociedade e estado, Brasília, v. 21, n. 1, abr. 2006. Disponível em: < http:// www.scielo.br/scielo.php?script=sci_arttext\&pid=S0102-69922006000100007 $\& \operatorname{lng}=\mathrm{en} \& \mathrm{nrm}=\mathrm{iso}>$. Acesso em: $1 \overline{6}$ mar. 2014.

23. TAMBOURIUS, E. et al. Introducing eParticipation: DEMO_net Consortium. IST Network of Excelence Project. 2007. Disponível em: <http://www.ifib.de/ publikationsdateien/Introducing_eParticipationDEMO-net_booklet_1.pdf $>$. Acesso em: 16 mar. 2007.

Recebido em: 05/06/2013

Aceite final: 17/12/2013 